Letter

\title{
Olefin Metathesis with Ru-Based Catalysts Exchanging the Typical $N$-Heterocyclic Carbenes by a Phosphine-Phosphonium Ylide
}

\author{
Laia Arnedo ${ }^{1}$, Remi Chauvin ${ }^{2,3, *}$ and Albert Poater ${ }^{2, *}$ \\ 1 Institut de Química Computacional i Catàlisi and Departament de Química, Universitat de Girona, \\ Campus Montilivi, 17003 Girona, Catalonia, Spain \\ 2 CNRS, LCC (Laboratoire de Chimie de Coordination), 205 Route de Narbonne, BP44099, \\ 31077 Toulouse CEDEX 4, France \\ 3 Université de Toulouse, UPS, ICT-FR 2599, 31062 Toulouse CEDEX 9, France \\ * Correspondence: remi.chauvin@lcc-toulouse.fr (R.C.); albert.poater@udg.edu (A.P.); \\ Tel.: +33-0561333113 (R.C.); +34-972418357 (A.P.)
}

Academic Editors: Albert Demonceau, Ileana Dragutan and Valerian Dragutan

Received: 2 February 2017; Accepted: 9 March 2017; Published: 14 March 2017

\begin{abstract}
Density functional theory (DFT) calculations have been used to describe the first turnover of an olefin metathesis reaction calling for a new in silico family of homogenous Ru-based catalysts bearing a phosphine-phosphonium ylide ligand, with ethylene as a substrate. Equal to conventional Ru-based catalysts bearing an $\mathrm{N}$-heterocyclic carbene (NHC) ligand, the activation of these congeners occurs through a dissociative mechanism, with a more exothermic first phosphine dissociation step. In spite of a stronger electron-donating ability of a phosphonium ylide C-ligand with respect to a diaminocarbene analogue, upper energy barriers were calculated to be on average ca. $5 \mathrm{kcal} / \mathrm{mol}$ higher than those of Ru-NHC standards. Overall, the study also highlights advantages of bidentate ligands over classical monodentate NHC and phosphine ligands, with a particular preference for the cis attack of the olefin. The new generation of catalysts is constituted by cationic complexes potentially soluble in water, to be compared with the typical neutral Ru-NHC ones.
\end{abstract}

Keywords: olefin metathesis; ruthenium; NHC; phosphine-phosphonium ylide; $N$-heterocyclic carbene; catalysis

\section{Introduction}

The fascinating history of olefin (or alkene) metathesis started almost five decades ago, when Anderson and Merckling published their observation of methine exchange by scission-migration of carbon-carbon double bonds in titanium-catalyzed polymerization of norbornene [1,2]. One decade later, Banks and Bailey reported a new comproportionation reaction converting dissymmetric alkenes to symmetric counterparts through elementary disproportionation processes $[3,4]$, what is now known as olefin metathesis. The methine exchange by cleavage-recombination of $\mathrm{C}=\mathrm{C}$ bonds requires promotion by metal catalysts [5], the design of which has long instigated a great deal of efforts in both academia [5,6] and industry [7]. Although the metallocyclobutane, an essential intermediate of the mechanism, was first proposed by Chauvin and Hérisson in the 1970s [8], the confirmation details did not arrive prior to the 1990s, finally ruling out the alternative process of [2+2] cycloadditions and cycloreversions [9]. Although all steps here are reversible, an efficient metathesis catalyst should follow a specific direction [10] through three sequential processes: initiation, propagation, and termination [11]. Consequently, the performance of the precatalyst can be mainly adjusted at either the levels of initiation or propagation, in particular by tuning the nature of spectator ligands at a $\mathrm{Ru}(\mathrm{II})$ center. After the 
first generation of Ru-based precatalysts involving two monophosphine ligands (Figure 1a), Grubbs et al. devised a second generation involving both phosphine and $\mathrm{N}$-heterocyclic carbene (NHC) ligands (Figure $1 \mathrm{~b}[12,13]$ and allowing dramatic accelerations of olefin metathesis reactions [14]. In spite of these key advances having opened the way to further improvements [15,16], many issues in homogeneous catalysis of olefin metathesis remain unclear, mainly regarding the mechanism [17], and possible guidelines for tuning the efficiency of particular catalysts [18].

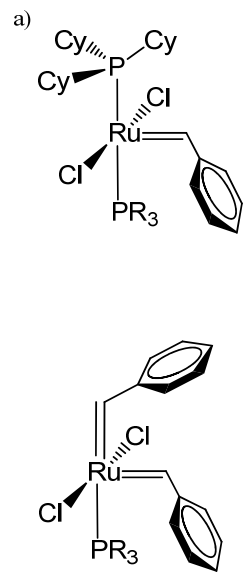

c)

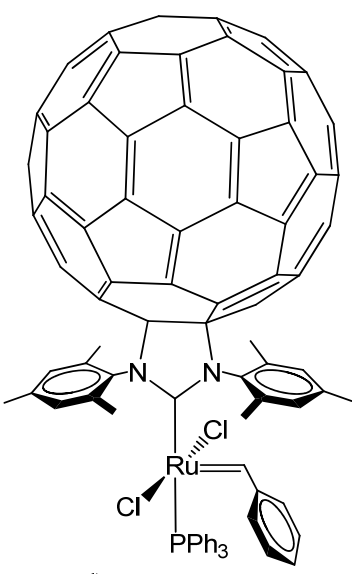

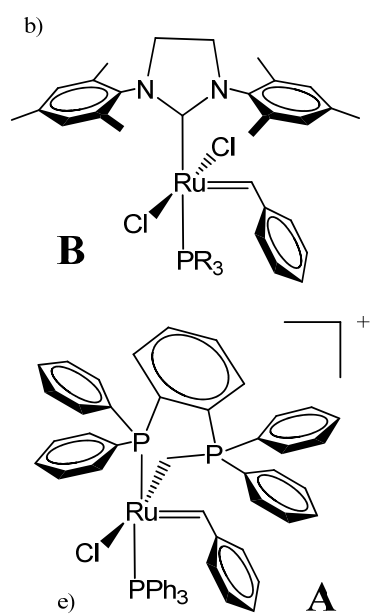

Figure 1. Classification of ruthenium precatalysts for olefin metathesis: (a) first generation; (b) second generation, and examples of futurist generations: (c) bis-benzylidene complex; (d) $\mathrm{C}_{60}-\mathrm{N}$-heterocyclic carbene (NHC)-based complex; and (e) phosphine-phosphonium ylide complex ( $\mathrm{R}=\mathrm{Ph}$ or Cy).

Most of the precatalysts envisaged to date are ruthenium complexes, even in recent computational studies where the NHC ligand of the second generation (Figure 1b) has been replaced by a second alkylidene ligand [19] (Figure 1c), or by a nanotechnology-inspired $\mathrm{C}_{60}-\mathrm{NHC}$ ligand (Figure 1d) [20]. In a complementary exploration approach, alternative transition metals have, however, been considered, such as iron [21-23], tungsten [24], or rhodium [25].

By comparison to phosphine parents, the chief value of diaminocarbenes as spectator neutral ligands in homogeneous catalysis is their stronger donor character, inducing a higher electron density at a metal center, while achieving a trade-off between the local Lewis acidity of the latter and the global stability of the complex (i.e., between the activity and lifetime of corresponding catalytic species). Regarding the catalytic activity, the specification satisfied by both phosphine and NHC ligands is the weak electronegativity and soft HSAB (hard soft acid base) character of the respective P- and $\mathrm{C}$-coordinating atoms. What about alternatives to NHCs as strong soft ligands? Just as aminocarbenes, phosphonium ylides are neutral and exhibit a prominent zwitterionic character $\left(\mathrm{P}^{+}-\mathrm{C}^{-}\right.$vs. $\left.\mathrm{N}^{+}=\mathrm{C}^{-}\right)$ with a strong C-coordinating ability [26-30]. In accordance with the lower acidic character of $\mathrm{sp}^{3}-\mathrm{CH}$ units of phosphoniums vs. $\mathrm{sp}^{2}-\mathrm{CH}$ units of the amidiniums, phosphonium methylides have been shown to act as stronger donors than imidazol-2-ylidene NHCs [31,32]. Replacement of the NHC moiety of Grubbs II catalysts by an ylide alternative is thus a natural investigation issue. As revealed by the zwitterionic resonant structure (Figure 2), ylides behave as $\eta^{1}$-X-type ligands (in the sense of the Green formalism), first inducing a zwitterionic metallate character at the $\mathrm{Ru}(\mathrm{II})^{-}$center [33]; the resulting electrostatic destabilization can thus be anticipated to promote dissociation of one the anionic $\mathrm{Cl}$ ligands, as previously shown possible in related contexts [34]. The coordinating ylide-bearing local analogy with the anionic $\mathrm{Cl}$ ligands, it could thus substitute one of them while making the Ru center electron-deficient with a 14-electron count. In order to concomitantly restore the 16-electron count, a pending 2-electron neutral donor is envisaged in the bidentate phosphine-phosphonium ylide $\mathrm{Ph}_{2} \mathrm{P}-\mathrm{C}_{6} \mathrm{H}_{4}-\mathrm{Ph}_{2} \mathrm{P}=\mathrm{CH}_{2}$, previously illustrated to behave as a $\mathrm{P}, \mathrm{C}$-chelating ligand in $\mathrm{Rh}(\mathrm{I})$ complexes $[35,36]$. Beyond their widest application in the Wittig 
reaction, phosphonium ylides-and in particular phosphine-phosphonium ylides-were punctually used as ligands in homogeneous catalysis, in particular, asymmetric catalysis [37-39]. Within this spirit, the performance of such ligands in olefin metathesis is hereafter addressed for the first time.

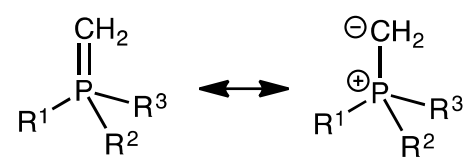

Figure 2. Resonant structures of a phosphonium ylide revealing the electron-richness and the electron-donating character of the carbon end, with propensity to adopt an $\mathrm{sp}^{3}$ hybridization state in a $\eta^{1}$-coordination mode toward a transition metal center.

To this end, the experimental exploration of the whole space of chemical catalysts to find new ones is often based on trial and error. Therefore, computational techniques constitute a popular and fast tool for finding new structures, potentially efficient as olefin metathesis catalysts. Already in the past, new catalysts were announced on the basis of density functional theory (DFT) predictions $[40,41]$. Here, a cationic phosphine-phosphonium ylide Ru-based complex is thus theoretically suggested as a potential catalyst for olefin metathesis (Figure 1e).

\section{Results}

In this study, the mechanism of ethylene metathesis (Figure 3) is computed for the Ru-based globally cationic complex A (Figure 1e) to be compared with the neutral complex $\mathbf{B}$ $\left(\mathrm{Ru}\right.$ (SIMes) $\mathrm{Cl}_{2}(=\mathrm{CHPh}) \mathrm{PPh}_{3}$, Figure $\left.1 \mathrm{~b}\right)$. The main focus is on the relative thermodynamic stability of the reaction intermediates of the complexes $\mathbf{A}$ and $\mathbf{B}$. In the system $\mathbf{A}$, the phosphine-phosphonium ylide ligand is $\mathrm{P}$-coordinated trans with respect to the leaving phosphine $\mathrm{PPh}_{3}$, while the methylenic moiety $\left(\mathrm{P}^{+} \mathrm{CH}_{2}\right)$ is $\mathrm{C}$-coordinated cis to the same $\mathrm{PPh}_{3}$ ligand, replacing the $\mathrm{Cl}$ ligand of the parent complex B.

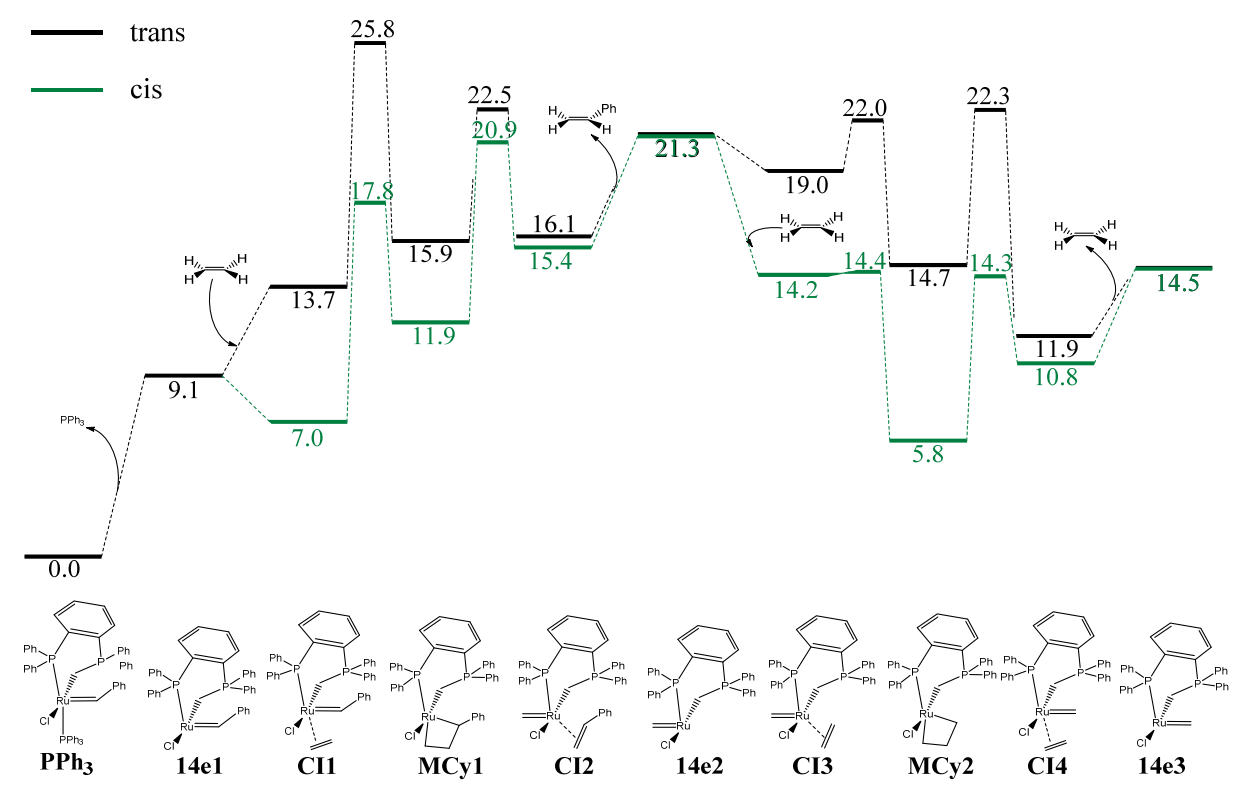

Figure 3. In-solvent $\left(\mathrm{CH}_{2} \mathrm{Cl}_{2}\right) \mathrm{M06} / \mathrm{TZVP} \sim \mathrm{SDD} / / \mathrm{BP} 86 / \mathrm{SVP} \sim \mathrm{SDD}$ free-energy profile for the olefin metathesis reaction catalyzed by complex $\mathbf{A}\left(\mathbf{A}=\mathbf{P P h}_{\mathbf{3}}\right.$ here) using ethylene as substrate (energies in $\mathrm{kcal} / \mathrm{mol}$ ). The cis and trans modes (in black and green, respectively) correspond to the regioselectivity of the coordination of ethylene with respect to the $\mathrm{PPh}_{2}$ moiety of the phosphine-phosphonium ylide ligand. 
After dissociation of the labile $\mathrm{PR}_{3}$ ligand, there are a priori two possibilities to coordinate the olefin at the ruthenium center of a Grubbs catalyst: cis or trans with respect to the stronger $\mathrm{PCy}_{3}$ or NHC ligand. Although most of the existing literature supports the trans coordination mode (demonstrated for the Grubbs II system B [42,43]), both pathways may exist depending on the type of ligand and nature of the olefin. Indeed, since 2000, several studies have tried to reveal the preference for the trans mode and/or find alternative ways to promote the cis mode [44,45]: the issue remains an open debate in NHC-ruthenium catalysis [46,47]. In summary, a trans binding preferential can be generally postulated, but the special nature of the present phosphine-phosphonium ylide ligand might provide an example where the olefin can be coordinated in the cis mode: Correa and Cavallo [48] indeed showed that the trans/cis selectivity was based on a delicate balance between steric and electronic effects, also depending on the solvent. Particularly, the phosphine-phosphonium ylide is, in principle, sterically more demanding than most of the NHCs, including the typical SIMes (1,3-bis(2,4,6-trimethylphenyl)-4,5-dihydroimidazol-2-ylidene) NHC ligand of the complex B. This could lead to a preference for the cis attack in phosphine-phosphonium ylide-based complexes, in agreement with statements by Goddard and Grubbs [49].

The energy profile of the first cycle of the catalytic reaction (i.e., activation of the catalyst A), was calculated according to the mechanism described in Figure 3. After the release of the labile ligand to form the 14e species of electrons (14e1), the remaining steps are the trans-coordination of the olefin (CI1), the metallacycle formation (MCy1), the proper metathesis leading to the styrene complex intermediate (CI2), and release of the styrene ligand affording the second 14e species (14e2). Having discussed the activation mechanism, the second part of the olefin metathesis reaction pathway is the propagation. For a better appraisal of the performance of catalyst $\mathbf{A}$, its catalytic energy profile is compared with that of the Grubbs II catalyst B in Figure 4.

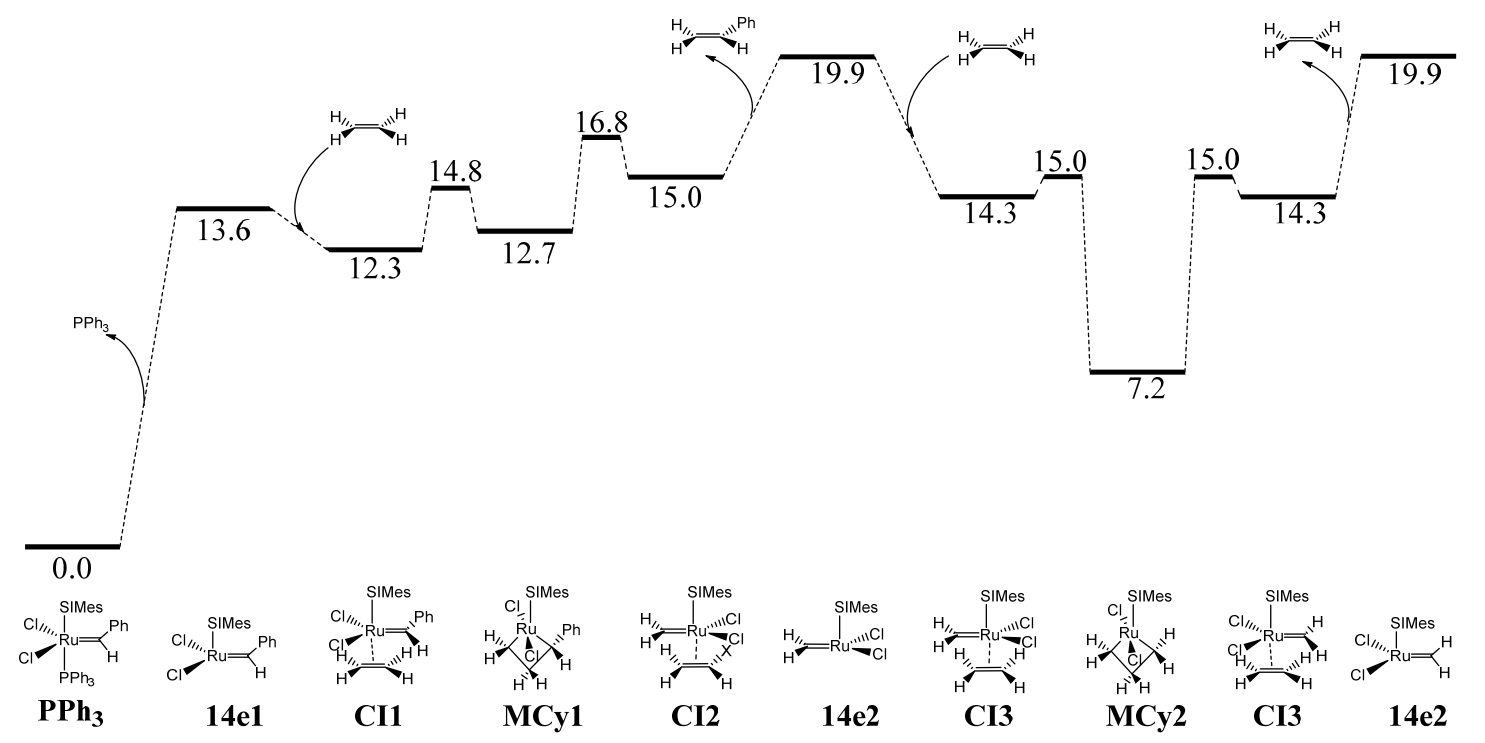

Figure 4. In-solvent $\left(\mathrm{CH}_{2} \mathrm{Cl}_{2}\right)$ free-energy profile for the olefin metathesis reaction of complex $\mathbf{B}$ ( $\mathbf{B}=\mathbf{P P h}_{\mathbf{3}}$ here) using ethylene as a substrate (calculated Gibbs energies at $298.15 \mathrm{~K}$ given in $\mathrm{kcal} / \mathrm{mol}$, SIMes = 1,3-Bis(2,4,6-trimethylphenyl)-4,5-dihydroimidazol-2-ylidene). The preferred trans mode is displayed.

Given the dissymmetry of the phosphine-phosphonium ylide ligand of complex A, the intermediates 14e2 and 14e3, as well as CI3 and CI4, are quite different compared to the corresponding intermediates from the symmetrical complex B (Figure 4) [50]. However, the phosphine-phosphonium ylide-based catalyst $\mathbf{A}$ might in fact be capable of promoting a reaction pathway perfectly consistent with a highly active catalyst in olefin metathesis (Figure 3). Going into 
details, the activation of the catalyst $\mathbf{A}$ begins with a simple dissociation of the $\mathrm{PPh}_{3}$ ligand, leading to the first 14e species 14e1, which in terms of energy is placed quite close to $\mathbf{A}$. In addition to the $9.1 \mathrm{kcal} / \mathrm{mol}$ required for the Ru-P bond cleavage, this step still would require to overcome a somewhat low energy barrier. The first two steps could also occur through a concerted pathway [51], but here this does not turn out to be a significant concern due to the low energy cost of the dissociation of the phosphine. Consequently, the dissociative mechanism should be favored by far.

In the next step, the olefin binds to the metal center in a trans mode leading to the intermediate trans-CI1, which is $4.6 \mathrm{kcal} / \mathrm{mol}$ above the 14e species 14e1. In contrast, the cis coordination mode to cis-CI1 is exergonic by $2.1 \mathrm{kcal} / \mathrm{mol}$. The following discussion will thus be based on an initial cis attack. The next step is a [2+2] cycloaddition process where $\mathbf{C I} \mathbf{1}$ collapses to a more stable intermediate, the metallacycle $\mathbf{M C} \mathbf{1} \mathbf{1}$, lying 4.9 and $11.9 \mathrm{kcal} / \mathrm{mol}$ above $\mathbf{C I} 1$ and $\mathbf{A}_{\mathbf{3}}$, respectively. A relatively cycloaddition barrier of $10.7 \mathrm{kcal} / \mathrm{mol}$ is calculated. A barrier of of $9.0 \mathrm{kcal} / \mathrm{mol}$ is calculated for the subsequent retro-cycloaddition, leading to CI2 while releasing the styrene ligand containing the initial benzylidene group. This generates the second $14 \mathrm{e}$ species $\mathbf{1 4} \mathbf{e}$, which is supposed to be the catalytically active species, resulting from an endothermic activation pathway by $21.3 \mathrm{kcal} / \mathrm{mol}$. Although this might be a drawback for the viability of the cationic catalyst, it is possible that the system evolves directly from $\mathbf{C I} 2$ to $\mathbf{C I} 3$ through an associative-dissociative pathway, since linear transit calculations go into this direction, dissociating the $\mathrm{CH}_{2}=\mathrm{CHPh}$ and bonding $\mathrm{CH}_{2}=\mathrm{CH}_{2}$ at the same time. The next steps for the propagation have lower barriers regarding the activation steps counterparts. Overall, the discussion via the trans insertion of the olefin is not advantageous since the cis attack is favorable by $6.7 \mathrm{kcal} / \mathrm{mol}$ from CI1. The energy difference of around $6 \mathrm{kcal} / \mathrm{mol}$ between the two types of attack remains for nearly all intermediates, except for CI2, where the difference decreases down to $0.7 \mathrm{kcal} / \mathrm{mol}$. These results are against the typical behavior of many classical catalysts, which favor the trans mechanism. However, the difference between the cis and trans attack is here not as clearcut as the preference for the trans attack from symmetrical NHC-based olefin metathesis catalysts such as $\mathbf{B}$.

The performance of catalyst A should be compared with that of catalyst B (Figure 4). The energy required to get rid of the phosphine turns out to be somewhat higher, $13.6 \mathrm{kcal} / \mathrm{mol}$, thus $4.5 \mathrm{kcal} / \mathrm{mol}$ more than for the phosphine-phosphonium ylide-based system $\mathbf{A}$. This is correlated with the stronger donating character of a phosphine-phosphonium ylide ligand as compared to a NHC-chloride ligand pair. Then, the reaction pathway from species $14 \mathrm{e} 1$ to $14 \mathrm{e} 2$ is quite similar, except for the more facile opening and closure of the metallacycle.

\section{Discussion}

Having described the reaction pathways for complexes $\mathbf{A}$ and $\mathbf{B}$, the analysis of the optimized structures for complex A unravels the feature that the phenyl substituents on phosphorous atoms are prone to stabilize the benzylidene group by means of $\pi-\pi$ stacking interactions (see Figure $5 \mathrm{a}$ ). On the other hand, the bidentate nature of the phosphine-phosphonium ylide ligand favors the much higher stability of the metallacycle for the cis attack from complex A, by 4.0 and $8.9 \mathrm{kcal}$ for MCy1 and MCy2, respectively, since the phenyl substituents of the $\mathrm{P}^{+}$center bonded to the methylenic unit leave the trans position to the other $\mathrm{P}$ atom less accessible, than the trans position to the NHC ligand for complex B. Indeed, a deeper structural analysis helps to understand how the environment changes when the metal replaces a NHC ligand by the phosphine-phosphonium ylide. The steric properties around the metal have been studied in detail, based on the species " $\mathbf{P P h}_{3}$ " and 14e1, for $\mathbf{A}$ and $\mathbf{B}$ (see Figure 6). We calculated the percent buried volume (\%VBur) by the phosphine-phosphonium ylide ligand of A and the NHC ligand of B [52], using the SambVca2 package developed by Cavallo et al. [53,54]. This program examines the first coordination sphere around the metal where the catalytic process takes place, and the buried volume is the measure of the first coordination sphere of the metal held by the donor ligand. It also allows a more detailed analysis to assess \%VBur in individual quadrants around the ruthenium center, and a representation of steric contour maps (Figure 6 and Table 1) [55]. Splitting 
the total \%VBur into quadrant contributions quantifies any asymmetry, due to the ligand around the metal. This analysis shows how to change the shape of the reaction cavity by going from $\mathbf{A}$ to $\mathbf{B}$.

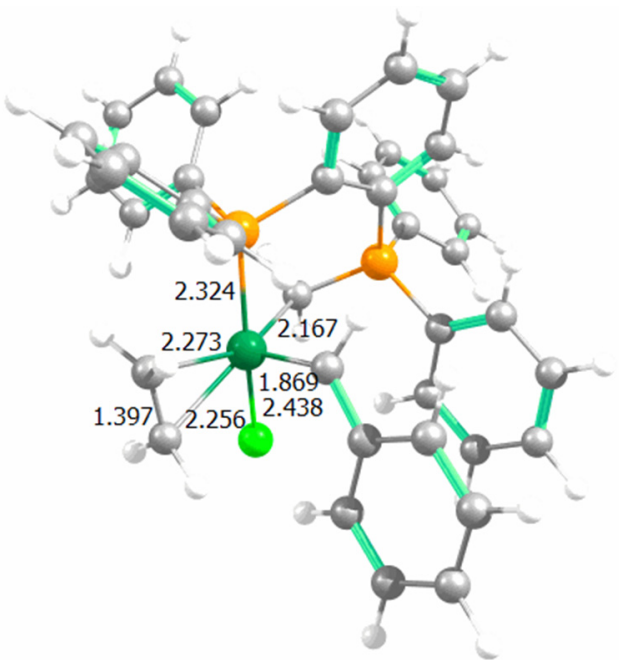

(a)

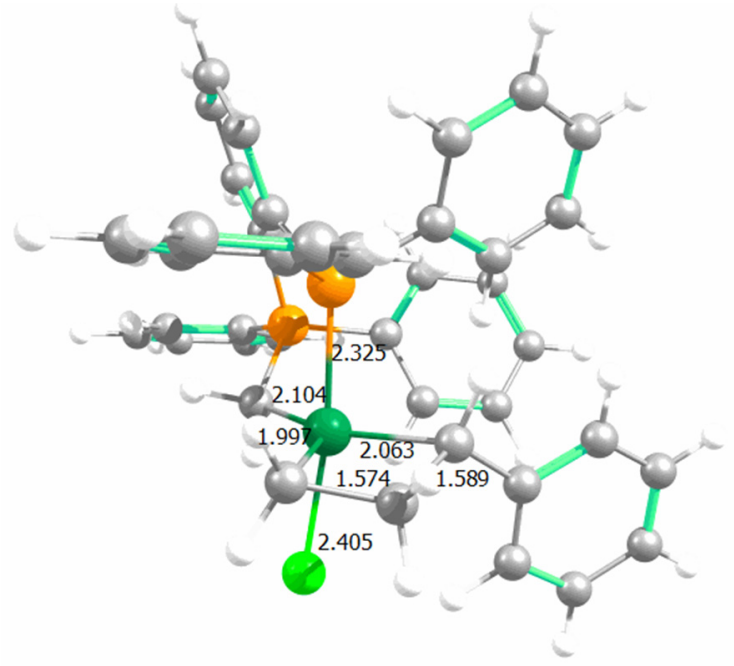

(b)

Figure 5. Calculated structures of selected intermediates (a) A-CI1-cis and (b) A-MCy1-cis (main distances in $\AA$; colours: dark green: $\mathrm{Ru}$; light green: $\mathrm{Cl}$; orange: P; gray: C; and white: $\mathrm{H}$ ).

Table 1. Total percent buried volume (\%VBur) and quadrant \%VBur (numbers in brackets) values for the species "PPh${ }_{3}$ " and $\mathbf{1 4 e 1}$ for the considered Ru-based complexes A and B.

\begin{tabular}{ccc}
\hline \multirow{2}{*}{ Complex } & \multicolumn{2}{c}{$\% V_{\text {Bur }}$} \\
\cline { 2 - 3 } & $\mathbf{A}$ & B \\
\hline $\mathbf{P P h}_{3}$ & $\mathbf{4 5 . 8}(77.6 / 33.1 / 28.2 / 44.3)$ & $\mathbf{3 3 . 4}(32.3 / 35.3 / 35.1 / 30.7)$ \\
$\mathbf{1 4 e 1}$ & $\mathbf{4 8 . 5 ( 8 0 . 6 / 3 5 . 8 / 3 1 . 8 / 4 5 . 6 )}$ & $\mathbf{3 6 . 4}(38.4 / 38.4 / 36.8 / 31.9)$ \\
\hline
\end{tabular}

As shown in Figure 6, the species "PPh ${ }_{3}$ " presents a quite different steric environment in the two complexes. The metal environment for complex $\mathbf{B}$ is significantly less sterically congested than for complex $\mathbf{A}$. In detail, the calculated percent buried volume (\%VBur) for complex $\mathbf{A}(45.8 \%)$ is much higher than for $\mathbf{B}(33.4 \%)$ (see Table 1). The difference between both 14e1 species for $\mathbf{A}$ and $\mathbf{B}$ is maintained, after dissociating the $\mathrm{PPh}_{3}$ ligand, whose dissociation should induce a relaxation of the ligands around the ruthenium center, which is transformed into an increase of the \%VBur of around 3\% for both complexes. Overall, the presence of the phosphine-phosphonium ylide ligand in A makes the metal environment more sterically hindered, the chelated phosphine-phosphonium ylide occupying two of the four quadrants more extensively. It should be noted that one of the quadrants is crowded because it includes the methylene group of the ylide end of the ligand. To sum up, despite the more sterically demanding metal center in complex $\mathbf{B}$, this hindrance does not preclude the coordination of any substrate, since there are at least two relatively free quadrants potentially accommodating towards an entering olefin [56]. It is true that the more sterically hindered ruthenium center generated from complex A favors the cis attack with respect to the trans attack, as expected and experimentally demonstrated for $\mathbf{B}$.

Going into details in terms of structure, Table 2 contains the main bond distances for complexes A and $\mathbf{B}$, whereas Table 3 includes Mayer bond orders (MBOs) measuring the strength of the bonds between the metal and the vicinal atoms. It is only after removal of the labile phosphine, that the Ru-P bond becomes stable, since the $\mathrm{MBO}$ for $\mathrm{PPh}_{3}$ is particularly low (0.662) even far from the unit. 


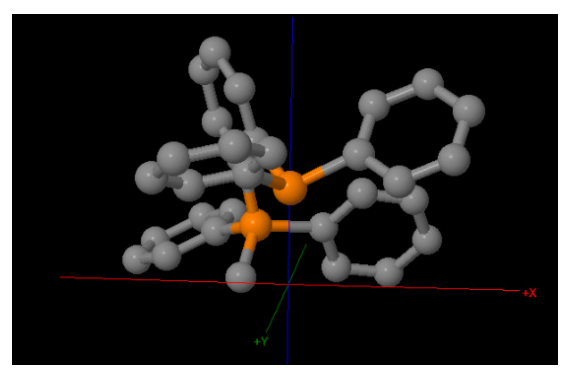

(a)

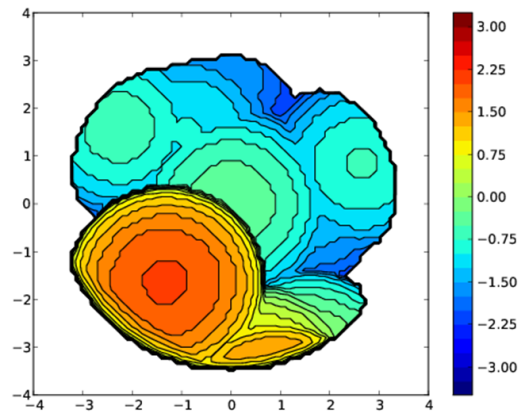

(c)

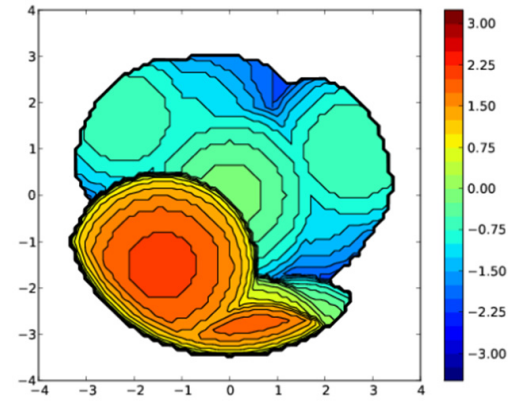

(e)

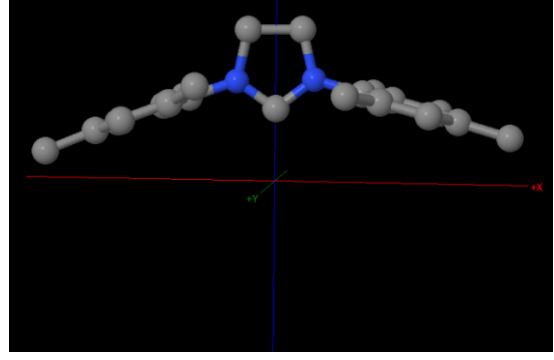

(b)

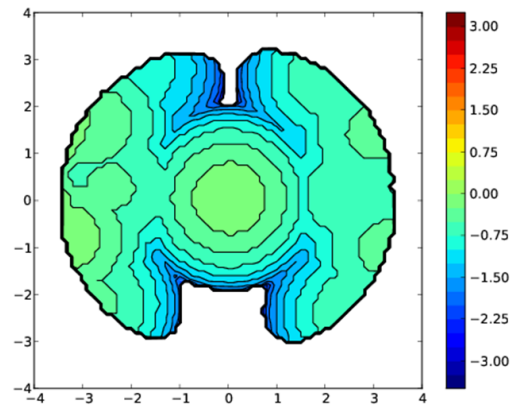

(d)

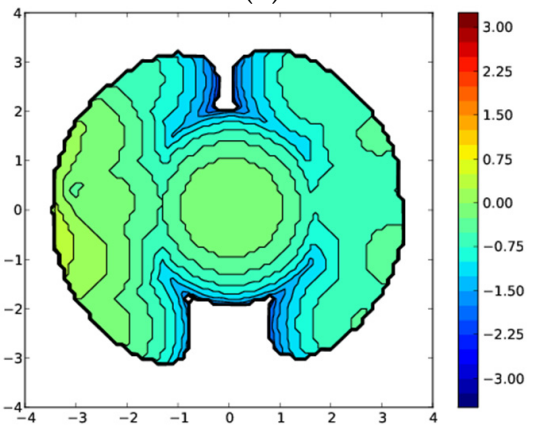

(f)

Figure 6. Orientation axes for the (a) phosphine-phosphonium ylide and (b) NHC ligand (colours: orange: P; gray: $\mathrm{C}$; and blue: $\mathrm{N}$ ); steric maps for the species " $\mathbf{P P h}_{\mathbf{3}}$ " corresponding to the complexes (c) A and (d) B; and steric maps for species 14e1 of complexes (e) A and (f) B. The Ru atom is at the origin and the $\mathrm{P}$ atom is on the $\mathrm{z}$ axis. The isocontour curves of the steric maps are given in $\AA$. The radius of the sphere around the metal center was set to $3.5 \AA$; the Bondi radii were scaled by 1.17 for all the atoms, and a mesh of $0.1 \AA$ was used to scan the sphere for buried voxels.

Table 2. Main distances for complexes A and B (in $\AA$ ).

\begin{tabular}{|c|c|c|c|c|c|c|}
\hline Complex & Species & $\mathrm{Ru}-\mathrm{Cl}$ & $\mathbf{R u}-\mathbf{P}_{\text {phosphine }}$ & $R \mathbf{u}=\mathrm{C}_{\text {methylenic }}$ & $\mathrm{Ru}=\mathrm{C}_{\text {ylidene }}$ & $\mathbf{R u}-\mathbf{P}_{(\mathbf{P h} 3)}$ \\
\hline \multirow{10}{*}{$\mathbf{A}$} & $\mathbf{P P h}_{3}$ & 2.427 & 2.338 & 2.109 & 1.857 & 2.429 \\
\hline & $14 \mathrm{e} 1$ & 2.307 & 2.200 & 2.093 & 1.850 & - \\
\hline & CI1 & 2.403 & 2.376 & 2.129 & 1.864 & - \\
\hline & MCy1 & 2.432 & 2.345 & 2.144 & 2.067 & - \\
\hline & CI2 & 2.397 & 2.324 & 2.137 & 2.456 & - \\
\hline & $14 \mathrm{e}^{2}$ & 2.306 & 2.235 & 2.111 & - & - \\
\hline & CI3 & 2.387 & 2.407 & 2.145 & 1.829 & - \\
\hline & МСy2 & 2.408 & 2.339 & 2.149 & 1.994 & - \\
\hline & CI4 & 2.465 & 2.397 & 2.170 & 1.819 & - \\
\hline & - & $\mathrm{Ru}-\mathrm{Cl}$ & $\mathrm{Ru}-\mathrm{C}_{\mathrm{NHC}}$ & $\mathrm{Ru}-\mathrm{Cl}_{\mathrm{bis}}$ & $\mathrm{Ru}=\mathrm{C}_{\text {ylidene }}$ & $\mathrm{Ru}-\mathrm{P}_{(\mathrm{Ph} 3)}$ \\
\hline \multirow{4}{*}{ B } & $\mathbf{P P h}_{3}$ & 2.442 & 2.039 & 2.421 & 1.850 & 2.400 \\
\hline & $14 \mathrm{e} 1$ & 2.323 & 1.921 & 2.331 & 1.845 & - \\
\hline & CI1 & 2.403 & 1.998 & 2.416 & 1.870 & - \\
\hline & МСу1 & 2.409 & 1.997 & 2.418 & 2.001 & - \\
\hline
\end{tabular}


Table 3. Mayer bond orders for complexes A and B (in $\AA$ ).

\begin{tabular}{ccccccc}
\hline Complex & Species & $\mathbf{R u}-\mathbf{C l}$ & $\mathbf{R u}-\mathbf{P}_{\text {phosphine }}$ & $\mathbf{R u}=\mathbf{C}_{\text {methylenic }}$ & $\mathbf{R u}=\mathbf{C}_{\mathbf{y l i d e n e}}$ & $\mathbf{R u}-\mathbf{P}_{(\mathbf{P h} 3)}$ \\
\hline \multirow{4}{*}{$\mathbf{A}$} & $\mathbf{P P h}_{\mathbf{3}}$ & 1.047 & 0.662 & 0.867 & 1.709 & 0.533 \\
& $\mathbf{1 4 e 1}$ & 1.150 & 1.073 & 0.843 & 1.671 & - \\
& $\mathbf{C I} \mathbf{1}$ & 1.071 & 0.619 & 0.834 & 1.677 & - \\
& $\mathbf{M C y} \mathbf{1}$ & 1.199 & 0.678 & 0.841 & 0.935 & - \\
\hline & $\mathbf{-}$ & $\mathrm{Ru}-\mathrm{Cl}$ & $\mathrm{Ru}-\mathrm{C}_{\mathrm{NHC}}$ & $\mathrm{Ru}-\mathrm{Cl}_{\mathrm{bis}}$ & $\mathrm{Ru}=\mathrm{C}_{\text {ylidene }}$ & $\mathrm{Ru}-\mathrm{P}_{(\mathrm{Ph} 3)}$ \\
& $\mathbf{P P h}$ & 0.894 & 1.712 & 1.068 & 0.887 & 0.543 \\
& $\mathbf{1 4 e 1}$ & 1.111 & 1.648 & 1.114 & 1.249 & - \\
& $\mathbf{C I} \mathbf{1}$ & 1.021 & 1.569 & 1.153 & 0.978 & - \\
& $\mathbf{M C y} \mathbf{1}$ & 1.029 & 1.009 & 1.099 & 0.945 & - \\
\hline
\end{tabular}

Table 4 contains the natural bond order (NBO) charges for complexes $\mathbf{A}$ and $\mathbf{B}$. The electrophilicity values of 235.7 and $294.8 \mathrm{kcal} / \mathrm{mol}$ correspond to the species " $\mathbf{P P h}_{3}$ " and $\mathbf{1 4} \mathbf{e} \mathbf{~ f o r ~ c o m p l e x ~ A ~ [ 5 7 ] , ~}$ thus highly reactive with respect to the corresponding neutral catalyst $\mathbf{B}$, with values of 102.0 and $90.7 \mathrm{kcal} / \mathrm{mol}$. The same trend is also followed from the chemical hardness, with values of 26.8 and $34.0 \mathrm{kcal} / \mathrm{mol}$ for "PPh 3 " and $\mathbf{M C y} \mathbf{1}$, respectively.

Table 4. Natural bond order (NBO) charges for complexes A and B (in $\AA$ ).

\begin{tabular}{|c|c|c|c|c|c|c|}
\hline Complex & Species & $\mathbf{R u}-\mathrm{Cl}$ & $\mathbf{R u}-\mathbf{P}_{\text {phosphine }}$ & $\mathbf{R u}=\mathrm{C}_{\text {ylidene }}$ & $\mathbf{R u}=\mathrm{C}_{\text {ylidene }}$ & $\mathbf{R u}-\mathbf{P}_{(\mathbf{P h} 3)}$ \\
\hline \multirow{5}{*}{ A } & $\mathrm{PPh}_{3}$ & -0.265 & 1.168 & -0.947 & 0.006 & 1.129 \\
\hline & 14e1 & -0.199 & 1.330 & -0.938 & -0.066 & - \\
\hline & CI1 & -0.240 & 1.172 & -0.924 & 0.017 & - \\
\hline & MCy1 & -0.312 & 1.203 & -0.945 & -0.155 & -0.315 \\
\hline & - & $\mathrm{Ru}-\mathrm{Cl}$ & $\mathrm{Ru}-\mathrm{C}_{\mathrm{NHC}}$ & $\mathrm{Ru}-\mathrm{Cl}$ & $\mathrm{Ru}=\mathrm{C}_{\text {ylidene }}$ & $\mathrm{Ru}-\mathrm{P}_{(\mathrm{Ph} 3)}$ \\
\hline \multirow{4}{*}{ B } & $\mathrm{PPh}_{3}$ & -0.311 & -0.012 & -0.316 & 0.429 & 1.131 \\
\hline & $14 \mathrm{e} 1$ & -0.255 & -0.026 & -0.249 & 0.505 & - \\
\hline & CI1 & -0.296 & 0.033 & -0.299 & 0.462 & - \\
\hline & МСу1 & -0.307 & -0.151 & -0.294 & 0.482 & -0.328 \\
\hline
\end{tabular}

\section{Materials and Methods}

All the DFT static calculations were performed with the Gaussian09.D01 set of programs [58]. The electronic configuration of the molecular systems was described with the standard split-valence basis set with a polarization function of Ahlrichs and coworkers for $\mathrm{H}, \mathrm{C}, \mathrm{N}, \mathrm{P}$, and $\mathrm{Cl}$ (SVP keyword in Gaussian) [59]. For Ru, the small-core, quasi-relativistic Stuttgart/Dresden effective core potential was used, with an associated valence basis set contracted (standard SDD keywords in gaussian09) [60]. The geometry optimizations were performed without symmetry constraints, and the characterization of the located stationary points was performed by analytical frequency calculations, by using the BP86 functional of Becke and Perdew [61,62], together with the Grimme D3 correction term to the electronic energy [63].

Single-point calculations of the BP86-D3 optimized geometries were performed by using the M06 functional [64] with the triple-z basis set of Weigend and Ahlrichs for main-group atoms (TZVP keyword in Gaussian) [65], whereas for ruthenium the SDD basis set was employed. Solvent effects were included with the polarizable continuous solvation model (PCM) using the dielectric constant of the $\mathrm{CH}_{2} \mathrm{Cl}_{2}$ solvent [66]. The reported free energies in this work include energies obtained at the M06/TZVP level of theory corrected with zero-point energies, thermal corrections, and entropy effects evaluated at $298 \mathrm{~K}$ and $1354 \mathrm{~atm}$, following the suggestion by Martin et al. [67], reconfirmed by Cavallo, Poater et al. in Ru-based olefin metathesis [68], with the BP86-D3/SVP method in the gas phase. In the Supporting Information, the free energies are reported at $p=1 \mathrm{~atm}$, too; however, bearing entropic contribution calculated at this value for pressure in the gas phase is probably exaggerating 
the expected values for the dissociative steps in the condensed phase [69], and $p=1354$ atm energy values seem to be more accurate ((see Figures S1 and S2, and Table S1).

\section{Conclusions}

DFT calculations have been used to explore the catalytic potential in ethylene metathesis of Ru-based complexes holding a phosphine-phosphonium ylide ligand instead of the innocent or inert NHC ligand. The thermodynamic stability of the reaction intermediates is close to the respective intermediates of complex bearing the classical SIMes NHC ligand, whereas the kinetics are predicted to be somewhat slower.

The activation mechanism of the discussed Ru-based catalyst was found to be similar to its $\mathrm{Ru}$-analogue bearing a SIMes NHC ligand occurring through dissociation of the labile ligand $\mathrm{PPh}_{3}$, but less energetically demanding when using the phosphine-phosphonium ylide as a trans ligand to the leaving $\mathrm{PPh}_{3}$. A geometrical and energetical analysis was accomplished for the Ru-based catalyst A through the first metathesis turnover, and the following propagation process. The reaction profile for catalyst $\mathbf{A}$ is consistent with an efficient Ru-based olefin metathesis catalyst. Bearing a similar structure with respect to well-known Ru catalysts, this new generation of olefin metathesis catalysts could turn out to be effective after experimental efforts. Conceptual DFT results show similar values with respect to the activity of the catalyst $\mathbf{B}$. However, steric maps are fundamental to rationalize why the rare cis attack of the entering olefin is favored for the complex A with respect to the usual trans attack preferred for the complex $\mathbf{B}$.

Supplementary Materials: The following are available online at www.mdpi.com/2073-4344/7/3/85/s1, Figure S1: Free-energy profile in solvent for the olefin metathesis reaction of complex A using ethylene as the substrate (energies in $\mathrm{kcal} / \mathrm{mol}$ calculated at $P=1 \mathrm{~atm}$ (instead of 1354); Figure S2: Free-energy profile in solvent for the olefin metathesis reaction of complex $\mathbf{B}$ using ethylene as the substrate (energies in $\mathrm{kcal} / \mathrm{mol}$ calculated at $P=1 \mathrm{~atm}$ (instead of 1354), SIMes = 1,3-Bis(2,4,6-trimethylphenyl)-4,5-dihydroimidazol-2-ylidene); Table S1: 3D view and xyz coordinate data sets and absolute energies in a.u. for DFT optimized complexes.

Acknowledgments: The Centre National de la Recherche Scientifique (CNRS) is acknowledged for half a teaching sabbatical for Remi Chauvin in 2015-2016. Albert Poater thanks the Spanish Ministry of Economy and Competitiveness (MINECO) for a project CTQ2014-59832-JIN and Xarxa de Química Teòrica i Computacional for a VALCHEM2016 project.

Author Contributions: Remi Chauvin and Albert Poater conceived and designed the experiments; Laia Arnedo and Albert Poater performed the experiments; Remi Chauvin and Albert Poater analyzed the data; all authors wrote the paper.

Conflicts of Interest: The authors declare no conflict of interest. The founding sponsors had no role in the design of the study; in the collection, analyses, or interpretation of data; in the writing of the manuscript, and in the decision to publish the results.

\section{References}

1. Anderson, A.W.; Merckling, N.G. Polymeric Bicycle [2.2.1]-2-heptene. Du Pont de Nemours \& Co. U.S. Patent 2,721,189, 18 October 1955.

2. Truett, W.L.; Johnson, D.R.; Robinson, I.M.; Montague, B.A. Polynorbornene by coordination polymerization. J. Am. Chem. Soc. 1960, 82, 2337-2340. [CrossRef]

3. Banks, R.L.; Bailey, G.C. Olefin disproportionation. A new catalytic process. Ind. Eng. Chem. Prod. Res. Dev. 1964, 3, 170-173. [CrossRef]

4. Calderon, N. Olefin metathesis reaction. Acc. Chem. Res. 1972, 5, 127-132. [CrossRef]

5. Vougioukalakis, G.C.; Grubbs, R.H. Ruthenium-based heterocyclic carbene-coordinated olefin metathesis catalysts. Chem. Rev. 2010, 110, 1746-1787. [CrossRef] [PubMed]

6. Rouen, M.; Queval, P.; Borré, E.; Falivene, L.; Poater, A.; Berthod, M.; Hugues, F.; Cavallo, L.; Baslé, O.; Olivier-Bourbigou, H.; et al. Selective metathesis of $\alpha$-olefins from bio-sourced Fischer-Tropsch feeds. ACS Catal. 2016, 6, 7970-7976. [CrossRef]

7. Pozgan, F.; Dixneuf, P.H. Metathesis chemistry. In Nanostructure Design to Synthesis of Advanced Materials; Springer: Dordrecht, The Netherlands, 2007; Volume 243, pp. 195-222. 
8. Hérisson, J.L.; Chauvin, Y. Catalyse de transformation des olefins par les complexes du tungstène. Makromol. Chem. 1971, 141, 161-176. [CrossRef]

9. Katz, T.J.; McGinnis, J. Mechanism of the olefin metathesis reaction. J. Am. Chem. Soc. 1975, 97, $1592-1594$. [CrossRef]

10. Perfetto, A.; Costabile, C.; Longo, P.; Bertolasi, V.; Grisi, F. Probing the relevance of NHC ligand conformations in the Ru-catalysed ring-closing metathesis reaction. Chem. Eur. J. 2013, 19, 10492-10496. [CrossRef] [PubMed]

11. Sanford, M.S.; Ulman, M.; Grubbs, R.H. New insights into the mechanism of ruthenium-catalyzed olefin metathesis reactions. J. Am. Chem. Soc. 2001, 123, 749-750. [CrossRef] [PubMed]

12. Credendino, R.; Poater, A.; Ragone, F.; Cavallo, L. A computational perspective of olefins metathesis catalyzed by $\mathrm{N}$-heterocyclic carbene ruthenium (pre) catalysts. Catal. Sci. Technol. 2011, 1, 1287-1297. [CrossRef]

13. Weskamp, T.; Schattenmann, W.C.; Spiegler, M.; Herrmann, W.A. A novel class of ruthenium catalysts for olefin metathesis. Angew. Chem. Int. Ed. 1998, 37, 2490-2493. [CrossRef]

14. Huang, J.; Stevens, E.D.; Petersen, J.L.; Nolan, S.P. Olefin metathesis-active ruthenium complexes bearing a nucleophilic carbene ligand. J. Am. Chem. Soc. 1999, 121, 2674-2678. [CrossRef]

15. Veldhuizen, J.J.V.; Garber, S.B.; Kingsbury, J.S.; Hoveyda, A.H. A recyclable chiral Ru catalyst for enantioselective olefin metathesis. Efficient catalytic asymmetric ring-opening/cross metathesis in air. J. Am. Chem. Soc. 2002, 124, 4954-4955. [CrossRef] [PubMed]

16. Samojłowicz, C.; Bieniek, M.; Grela, K. Ruthenium-based olefin metathesis catalysts bearing $N$-heterocyclic carbene ligands. Chem. Rev. 2009, 109, 3708-3742. [CrossRef] [PubMed]

17. Nelson, D.J.; Manzini, S.; Urbina-Blanco, C.A.; Nolan, S.P. Key processes in ruthenium-catalysed olefin metathesis. Chem. Commun. 2014, 50, 10355-10375. [CrossRef] [PubMed]

18. Poater, A.; Bahri-Laleh, N.; Cavallo, L. Rationalizing current strategies to protect N-heterocyclic carbene-based ruthenium catalysts active in olefin metathesis from C-H (de)activation. Chem. Commun. 2011, 47, 6674-6676. [CrossRef] [PubMed]

19. Poater, A.; Credendino, R.; Slugovc, C.; Cavallo, L. Exploring new generations of ruthenium olefin metathesis catalysts: The reactivity of a bis-ylidene ruthenium complex by DFT. Dalton Trans. 2013, 42, 7271-7275. [CrossRef] [PubMed]

20. Martínez, J.P.; Vummaleti, S.V.C.; Falivene, L.; Nolan, S.P.; Cavallo, L.; Solà, M.; Poater, A. In silico olefin metathesis with Ru-based catalysts containing $N$-heterocyclic carbenes bearing $\mathrm{C}_{60}$ fullerenes. Chem. Eur. J. 2016, 22, 6617-6623. [CrossRef] [PubMed]

21. Poater, A.; Vummaleti, S.V.C.; Pump, E.; Cavallo, L. Comparing Ru and Fe-catalyzed olefin metathesis. Dalton Trans. 2014, 43, 11216-11220. [CrossRef] [PubMed]

22. Poater, A.; Pump, E.; Vummaleti, S.V.C.; Cavallo, L. The activation mechanism of Fe-based olefin metathesis catalysts. Chem. Phys. Lett. 2014, 610-611, 29-32. [CrossRef]

23. De Brito Sá, E.; Rodríguez-Santiago, L.; Sodupe, M.; Solans-Monfort, X. Toward olefin metathesis with iron carbene complexes: Benefits of tridentate $\sigma$-donating ligands. Organometallics 2016, 35, 3914-3923.

24. Poater, A.; Solans-Monfort, X.; Clot, E.; Copéret, C.; Eisenstein, O. DFT calculations of d ${ }^{0} M(\mathrm{NR})(\mathrm{CH} t \mathrm{Bu})$ $(X)(Y)\left(M=\mathrm{Mo}, \mathrm{W} ; \mathrm{R}=\mathrm{CPh}_{3}, 2,6-\mathrm{Pr}-\mathrm{C}_{6} \mathrm{H}_{3} ; X\right.$ and $\left.Y=\mathrm{CH}_{2} t \mathrm{Bu}, \mathrm{O} t \mathrm{Bu}, \mathrm{OSi}(\mathrm{O} t \mathrm{Bu})_{3}\right)$ olefin metathesis catalysts: Structural, spectroscopic and electronic properties. Dalton Trans. 2006. [CrossRef] [PubMed]

25. Poater, A. Moving from classical Ru-NHC to neutral or charged Rh-NHC based catalysts in olefin metathesis. Molecules 2016, 21, 177. [CrossRef] [PubMed]

26. Schmidbaur, H. Phosphorus ylides in the coordination sphere of transition metals: An inventory. Angew. Chem. Int. Ed. 1983, 22, 907-927. [CrossRef]

27. Vicente, J.; Chicote, M. The 'acac method' for the synthesis of coordination and organometallic compounds: Synthesis of gold complexes. Trans. Coord. Chem. Rev. 1999, 193-195, 1143-1161. [CrossRef]

28. Vignolle, J.; Donnadieu, B.; Bourissou, D.; Soleilhavoup, M.; Bertrand, G. Cyclic C-amino phosphorus ylides as a source of bidentate heteroditopic ligands (phosphine/aminocarbene) for transition metals. J. Am. Chem. Soc. 2006, 128, 14810-14811. [CrossRef] [PubMed]

29. Transition Metal Complexes of Neutral $\eta^{1}$-Carbon Ligands; Chauvin, R., Canac, Y., Eds.; Springer: Berlin, Germany, 2010; pp. 1-256. 
30. Canac, Y.; Chauvin, R. Atropochiral C,X- and C,C-chelating carbon ligands. Eur. J. Inorg. Chem. 2010, 16, 2325-2335. [CrossRef]

31. Canac, Y.; Lepetit, C.; Abdalilah, M.; Duhayon, C.; Chauvin, R. Diaminocarbene and phosphonium ylide ligands: A systematic comparison of their donor character. J. Am. Chem. Soc. 2008, 130, 8406-8413. [CrossRef] [PubMed]

32. Lepetit, C.; Maraval, V.; Canac, Y.; Chauvin, R. On the nature of the dative bond: Coordination to metals and beyond. The carbon case. Coord. Chem. Rev. 2016, 308, 59-75. [CrossRef]

33. Chauvin, R. Zwitterionic organometallates. Eur. J. Inorg. Chem. 2000, 4, 577-591. [CrossRef]

34. Leitgeb, A.; Abbas, M.; Fischer, R.C.; Poater, A.; Cavallo, L.; Slugovc, C. Latent ruthenium based olefin metathesis catalyst with a sterically demanding NHC ligand (pre)catalysts. Catal. Sci. Technol. 2012, 2, 1640-1643. [CrossRef]

35. Viau, L.; Lepetit, C.; Commenges, G.; Chauvin, R. Chiral phosphine-phosphonium ylide rhodium complexes. Organometallics 2001, 20, 808-810. [CrossRef]

36. Zurawinski, R.; Donnadieu, B.; Mikolajczyk, M.; Chauvin, R. Chiral phosphino(sulfinylmethyl) triarylphosphonium ylide ligands: Rhodium complexes and catalytic properties. Organometallics 2003, 22, 4810-4817. [CrossRef]

37. Viau, L.; Chauvin, R. 'Diopium', a chiral phosphoniophosphine derived from Kagan's diop: Rhodium complexes and reducing catalytic properties. J. Organomet. Chem. 2002, 654, 180-186. [CrossRef]

38. Ohta, T.; Sasayama, H.; Nakajima, O.; Kurahashi, N.; Fujii, T.; Furukawa, I. Asymmetric allylic substitution catalyzed by palladium Yliphos complex. Tetrahedron Asymmetry 2003, 14, 537-542. [CrossRef]

39. Canac, Y.; Duhayon, C.; Chauvin, R. A Diaminocarbene-phosphonium ylide: Direct access to C,C-chelating ligands. Angew. Chem. Int. Ed. 2007, 46, 6313-6315. [CrossRef] [PubMed]

40. Chu, Y.; Heyndrickx, W.; Occhipinti, G.; Jensen, V.R. An evolutionary algorithm for de novo optimization of functional transition metal compounds. J. Am. Chem. Soc. 2012, 134, 8885-8895. [CrossRef] [PubMed]

41. Rissner, F.; Ma, M.Y.; Hofmann, O.T.; Slugovc, C.; Shuai, Z.; Zojer, E. Radical self-assembled monolayers on $\mathrm{Au}(111)$ formed by the adsorption of closed-shell molecules. J. Mater. Chem. 2012, 22, 4269-4272. [CrossRef]

42. Poater, A.; Ragone, F.; Correa, A.; Cavallo, L. Comparison of different ruthenium-alkylidene bonds in the activation step with $\mathrm{N}$-heterocyclic carbene Ru-catalysts for olefins metathesis. Dalton Trans. 2011, 40, 11066-11069. [CrossRef] [PubMed]

43. Bantreil, X.; Citadelle, C.A.; Slawin, A.M.Z.; Cazin, C.S.J. Phosphites as ligands in ruthenium-benzylidene catalysts for olefin metathesis. Chem. Commun. 2011, 47, 7060-7062.

44. Romero, P.E.; Piers, W.E. Mechanistic studies on 14-electron ruthenacyclobutanes: Degenerate exchange with free ethylene. J. Am. Chem. Soc. 2007, 129, 1698-1704. [CrossRef] [PubMed]

45. Poater, A.; Correa, A.; Pump, E.; Cavallo, L. Cis/trans coordination in olefin metathesis by static and molecular dynamic DFT calculations. Chem. Heter. Comp. 2014, 3, 424-430. [CrossRef]

46. Benitez, D.; Tkatchouk, E.; Goddard, W.A. Relevance of cis- and trans-dichloride Ru intermediates in Grubbs-II olefin metathesis catalysis $\left(\mathrm{H}_{2} \mathrm{IMesCl}_{2} \mathrm{Ru}=\mathrm{CHR}\right)$. Chem. Commun. 2008, 46, 6194-6196. [CrossRef] [PubMed]

47. Vidavsky, Y.; Anaby, A.; Lemcoff, N.G. Chelating alkylidene ligands as pacifiers for ruthenium catalysed olefin metathesis. Dalton Trans. 2012, 41, 32-43. [CrossRef] [PubMed]

48. Correa, A.; Cavallo, L. The elusive mechanism of olefin metathesis promoted by (NHC)Ru-based catalysts: A trade between steric, electronic, and solvent effects. J. Am. Chem. Soc. 2006, 128, 13352-13353. [CrossRef] [PubMed]

49. Benitez, D.; Goddard, W.A., III. The isomerization equilibrium between cis and trans chloride ruthenium olefin metathesis catalysts from quantum mechanics calculations. J. Am. Chem. Soc. 2005, 127, 12218-12219. [CrossRef] [PubMed]

50. Poater, A.; Cavallo, L. A comprehensive study of olefin metathesis catalyzed by Ru-based catalysts. Beilstein J. Org. Chem. 2015, 11, 1767-1780. [CrossRef] [PubMed]

51. Urbina-Blanco, C.A.; Poater, A.; Lebl, T.; Manzini, S.; Slawin, A.M.Z.; Cavallo, L.; Nolan, S.P. The activation mechanism of $\mathrm{Ru}$-indenylidene complexes in olefin metathesis. J. Am. Chem. Soc. 2013, 135, 7073-7079. [CrossRef] [PubMed] 
52. Falivene, L.; Credendino, R.; Poater, A.; Petta, A.; Serra, L.; Oliva, R.; Scarano, V.; Cavallo, L. SambVca 2. A web tool for analyzing catalytic pockets with topographic steric maps. Organometallics 2016, 35, $2286-2293$. [CrossRef]

53. Jacobsen, H.; Correa, A.; Poater, A.; Costabile, C.; Cavallo, L. Understanding the M-(NHC) (NHC = N-heterocyclic carbene) bond. Coord. Chem. Rev. 2009, 253, 687-703. [CrossRef]

54. Poater, A.; Cosenza, B.; Correa, A.; Giudice, S.; Ragone, F.; Scarano, V.; Cavallo, L. SambVca: A web application for the calculation of buried volumes of $N$-heterocyclic carbene ligands. Eur. J. Inorg. Chem. 2009, 1759-1766. [CrossRef]

55. Ahmed, S.M.; Poater, A.; Childers, M.I.; Widger, P.C.B.; LaPointe, A.M.; Lobkovsky, E.B.; Coates, G.W.; Cavallo, L. Enantioselective polymerization of epoxides using biaryl-linked bimetallic cobalt catalysts: A mechanistic study. J. Am. Chem. Soc. 2013, 135, 18901-18911. [CrossRef] [PubMed]

56. Poater, A.; Falivene, L.; Urbina-Blanco, C.A.; Manzini, S.; Nolan, S.P.; Cavallo, L. How does the addition of steric hindrance to a typical $N$-heterocyclic carbene ligand affect catalytic activity in olefin metathesis? Dalton Trans. 2013, 42, 7433-7439. [CrossRef] [PubMed]

57. Parr, R.G.; von Szentpaly, L.; Liu, S. Electrophilicity Index. J. Am. Chem. Soc. 1999, 121, 1922-1924. [CrossRef]

58. Frisch, M.J.; Trucks, G.W.; Schlegel, H.B.; Scuseria, G.E.; Robb, M.A.; Cheeseman, J.R.; Scalmani, G.; Barone, V.; Mennucci, B.; Petersson, G.A.; et al. Gaussian 09, Revision D.01; Gaussian, Inc.: Wallingford, CT, USA, 2009.

59. Schaefer, A.; Horn, H.; Ahlrichs, R. Fully optimized contracted Gaussian basis sets for atoms Li to Kr. J. Chem. Phys. 1992, 97, 2571-2577. [CrossRef]

60. Haeusermann, U.; Dolg, M.; Stoll, H.; Preuss, H. Accuracy of energy-adjusted quasirelativistic ab initio pseudopotentials. Mol. Phys. 1993, 78, 1211-1224. [CrossRef]

61. Becke, A. Density-functional exchange-energy approximation with correct asymptotic behaviour. Phys. Rev. A 1988, 38, 3098-3100. [CrossRef]

62. Perdew, J.P. Density-functional approximation for the correlation energy of the inhomogeneous electron gas. Phys. Rev. B 1986, 33, 8822-8824. [CrossRef]

63. Grimme, S.; Antony, J.; Ehrlich, S.; Krieg, H. A consistent and accurate ab initio parametrization of density functional dispersion correction (DFT-D) for the 94 elements H-Pu. J. Chem. Phys. 2010, 132, 154104. [CrossRef] [PubMed]

64. Zhao, Y.; Truhlar, D.G. The M06 suite of density functionals for main group thermochemistry, thermochemical kinetics, noncovalent interactions, excited states, and transition elements: Two new functionals and systematic testing of four M06-class functionals and 12 other functionals. Theor. Chem. Acc. 2008, 120, 215-241.

65. Weigend, F.; Ahlrichs, R. Balanced basis sets of split valence, triple zeta valence and quadruple zeta valence quality for H to Rn: Design and assessment of accuracy. Phys. Chem. Chem. Phys. 2005, 7, 3297-3305. [CrossRef] [PubMed]

66. Tomasi, J.; Persico, M. Molecular interactions in solution: An overview of methods based on continuous distributions of the solvent. Chem. Rev. 1994, 94, 2027-2094. [CrossRef]

67. Martin, R.L.; Hay, P.J.; Pratt, L.R. Hydrolysis of ferric ion in water and conformational equilibrium. J. Phys. Chem. A 1998, 102, 3565-3573. [CrossRef]

68. Poater, A.; Pump, E.; Vummaleti, S.V.C.; Cavallo, L. The right computational recipe for olefin metathesis with Ru-based catalysts: The whole mechanism of ring-closing olefin metathesis. J. Chem. Theory Comput. 2014, 10, 4442-4448. [CrossRef] [PubMed]

69. García-Melchor, M.; Pacheco, M.C.; Nájera, C.; Lledós, A.; Ujaque, G. Mechanistic exploration of the Pd-catalyzed copper-free Sonogashira reaction. ACS Catal. 2012, 2, 135-144. [CrossRef]

(c) 2017 by the authors. Licensee MDPI, Basel, Switzerland. This article is an open access article distributed under the terms and conditions of the Creative Commons Attribution (CC BY) license (http:/ / creativecommons.org/licenses/by/4.0/). 